\title{
ИСПОЛЬЗОВАНИЕ ИННОВАЦИОННЫХ СРЕДСТВ АВТОМАТИЗАЦИИ ДЛЯ АНАЛИЗА ВЛИЯНИЯ РАЗВИТИЯ ИНФОРМАЦИОННОЙ СРЕДЫ НА БЛАГОПОЛУЧИЕ ЧЕЛОВЕКА В КОНТЕКСТЕ ЦИФРОВОЙ ТРАНСФОРМАЦИИ
}

\author{
(C) 2021 Лямин Борис Михайлович
}

кандидат экономических наук, старший преподаватель Высшей школы сервиса и торговли Санкт-Петербургский политехнический университет Петра Великого, Россия, Санкт-Петербург E-mail: Lyamin.bm@gmail.com

\section{(c) 2021 Конников Евгений Александрович}

кандидат экономических наук, доцент Высшей инженерно-экономической школы Санкт-Петербургский политехнический университет Петра Великого, Россия, Санкт-Петербург

В статье проведен глубокий анализ существующих исследований по влиянию информационной среды на психологическое здоровье человека. При помощи современных методов анализа были выявлены факторы, оказывающие значительное влияние на психологическое здоровье человека. Подтверждена зависимость психологического здоровья человека от внедрения инновационных технологий в области ИКТ. Данная зависимость подчеркивает возможность усиления рисков и необходимости их дальнейшего исследования, в результате цифровой трансформации экономики России.

Ключевые слова: цифровая трансформация, инновационные технологии, анализ данных, информационная среда, новостной фон, Pуthon

В современном обществе информационная среда, окружающая человека, стремительно развивается, становясь все более обширной и разнообразной. Количество информации, которое постоянно воздействует на человека увеличивается, при этом создаются и совершенствуются все новые способы и инструменты доставки информации до человека. Например, несколько лет назад обучение в высшем учебном заведении даже по заочной форме обучения происходило лишь в очном формате, т.е. студенты приезжали на сессию, получали информацию, которая входит в их учебный план, сдавали экзамены и зачеты и уезжали обратно. В настоящее время в связи с ограничительными мерами, вызванными новой коронавирусной инфекцией COVID-19 абсолютное большинство высших учебных заведений временно перешли на дистанционный формат образования, при этом обязательным стало прохождение онлайн курсов для получения оценки по тем или иным предметам. Все это значительно увеличивает поток информации студента, и он не всегда имеет возможность ее усвоить и отрефлексировать [7, 12]. Развитие научно-технологического прогресса открывает множество возможностей, оказывая влияние на образ жизни и делая его более практичным и удобным. Такие изменения влияют на потребности личности и мотивацию, приводят к перестройке образа жизни и мировоззрения. С помощью информационных потоков общество передает каждому из нас принятые нормы, ценности, стереотипы и так далее.

В связи с этим информационная среда оказывает влияние и на психологическую сторону личности и эффект такого воздействия зависит от множества факторов, присущих как информационной среде, так и самой личности. Например, такими факторами могут являться: количественная и качественная характеристика информации (ее объем, полнота, достоверность и т.д.) или, если говорить о факторах, присущих самой личности, то к ним можно отнести неспособность к фильтрации получаемой информации, подверженность манипулятивным действиям со стороны, ментальные заболевания, психоэмоциональный стресс, тревожность и т.д.

Ввиду того, что применение современных информационно-коммуникационных технологий формирует информационную среду вокруг человека, в частности научно-педагогического работника или студента, то необходимо оценить риски, которые несет в себе информационная среда.

Информационная среда, которую можно отнести к социальным факторам воздействия на 
психику человека, не является однородной, она состоит из множества процессов, протекающих с разной скоростью, также в ней присутствует как информация, объективно отражающая реальность, так и информация, создающая неверное представление об объекте.

Также опасность для психологического здоровья могут представлять различные группы людей политической, националистической или религиозной направленности, распространяющие свое влияние через сеть. К сожалению, зачастую члены таких сообществ используют различные психологические манипулятивные методы воздействия на личность, которые оказывают негативное влияние на психику человека.

Проведем анализ статей, в которых исследуются риски воздействия информационной среды на человека. Авторы Задохина Н.В. и Попова Г.Г. в статье «Психологическое воздействие информационной среды на современного человека», отмечают, что влияние информационных технологий на личностное развитие не может быть однозначно квалифицировано как положительное или отрицательное [9]. При частом использовании компьютера и Интернета могут возникнуть психологические проявления интернет-зависимости, которая выражается в большом количестве проблем поведения и контроля над влечениями и в итоге приводит к изменению личности в целом. Кроме интернет-зависимости выделяют и номофобию - зависимость от смартфонов. Она вызывает у человека чувство тревоги, связанное с невозможностью пользоваться мобильным телефоном.

Согласно результатам, одного из исследований, представленного в статье «The drawbacks of Information and Communication Technologies: Interplay and psychopathological risk of nomophobia and cyber-bullying, results from the bullying and youth mental health Naples study», номофобия тесно связана с таким понятием, как «кибербуллинг» (форма агрессии, осуществляемая в электронном контексте, то есть в блоге, чате, социальных сетях и так далее). Люди с высоким уровнем зависимости более склонны демонстрировать агрессивное поведение в сети, чем другие пользователи [1]. Оба феномена связаны с эмоциональными проблемами, гиперактивностью, проблемами поведения и так далее. Поэтому имеет место быть потенциальное воздействие на ментальное здоровье.
Однако, согласно другому исследованию «Avoidance or boredom: Negative mental health outcomes associated with use of Information and Communication Technologies depend on users' motivations», не всегда высокая вовлеченность в использование сотовых телефонов приносит вред [6]. Если устройства используются для избавления от скуки, что бывает довольно часто, это не приносит никакого вреда, что, впрочем, является довольно очевидным выводом.

При этом, частое использование ИКТ связано с попыткой избавиться или отвлечься от тревоги и депрессии. Люди пытаются достичь «эффекта защитного одеяла», что в краткосрочном периоде позволяет человеку успокоиться и прийти в некоторое состояние равновесия, но в долгосрочной перспективе частое использование ИКТ для снятия эмоционального напряжения может оказывать негативное влияние на психическое здоровье и/или усугублять предрасположенность к тем или иным ментальным заболеваниям [8].

Согласно результатам исследования «Internet addiction severity and risk for psychopathology, serious mental illness, and suicidalities: a crosssectional study» распространённость и риск проявления ментальных болезней прямо пропорциональны тяжести интернет-зависимости [3]. К сожалению, аналогичная картина складывается и относительно суицидальных мыслей (планов и попыток), что не может быть не связано с психологическим состоянием. Кроме того, учитывая все вышесказанное, нельзя отрицать обоснованность определения умеренной и тяжелой степени интернет-зависимости, как психического заболевания.

Таким образом, отмеченные выше проблемы в первую очередь касаются молодых людей в возрасте 14-18 лет, что связано с их физиологическими особенностями. Остро протекающий психический перелом обусловливает его исключительную сложность и противоречивость.

Как известно, любая деятельность направлена на удовлетворение потребностей. Спектр базовых потребностей современного молодого человека достаточно широк. Помимо базовых (физиологических и безопасности), среди них важное место занимают социальные потребности (общения, любви, признания) и потребности, связанные с развитием личности (познания, понимания, самореализации). В результате использования Интернета возникает ощущение 
полного контроля и владения ситуацией, которое, к сожалению, может быть весьма обманчивым. В связи с этим можно выделить факторы риска формирования интернет-зависимости (чрезмерного использования ИКТ, номофобии и т.д.), связаные со следующими личностными особенностями подростков: склонностью к поиску новых ощущений, агрессивностью и тревожностью, эмоциональной отчужденностью, низкой коммуникативной компетентностью и др.

Согласно исследованию группы авторов A. McCrory, P. Best и A. Maddock удалось выяснить, что использование высоковизуальных социальных сетей зачастую вызывает зацикленность на собственной внешности и часто - недовольство своим внешним видом, как следствие, - депрессию. Помимо этого, регулярное использование «Инстаграма» вызывает сильную зависимость от гаджета, связанную со страхом пропустить важные события и новости, публикуемые в «Инстаграме». Это является определяющим фактором в развитии бессонницы, общей тревожности, беспокойства и так далее [4].

В исследовании ЕжевскойТ.И. негативное воздействие на психику человека в интернете могут оказать различные группировки людей политической, националистической или религиозной направленности, которые распространяют свое влияние именно с помощью сети, кибербуллинг, азартные игры или же просто мошенники [8].

Проблему воздействия глобальной повестки на психологическое здоровье рассмотрел J.M.Cénat. В результате проведенного исследования автор отмечает, что глобализация так же может оказывать негативное воздействие на психику человека [2]. Наиболее вероятно это связано с огромным потоком информации, содержащим в себе обширные и разнообразные, а иногда и противоречивые знания о культуре, религии, нормах морали, ценностях и так далее.

Что подтверждается исследованием D.M. de Miranda и B. da Silva Athanasio, которые выявили негативное влияние информационного фона содержащего информацию о новой коронавирусной инфекции на психику, вызывая более высокий уровень стресса [5]. У многих людей наблюдаются более выраженные симптомы тревоги и депрессии.

Таким образом, в результате проведенного исследования были выявлены факторы, которые могут оказывать влияние на благополучие чело- века и факторы на которые оказывается влияние для дальнейшего анализа:

1. Число зарегистрированных больных с диагнозом психического расстройства и расстройствами поведения;

2. Число зарегистрированных умерших по причине самоубийства (данный показатель взят в качестве зависимого, как крайняя степень того, к чему может привести ментальное заболевание);

Факторы развития информационной среды:

3. Количество ПК;

4. Доля населения, пользующегося информационно-телекоммуникационной сетью «Интернет»;

5. Цифровизация телефонной сети;

6. Доходы от услуг радиосвязи, радиовещания, телевидения и спутниковой связи;

7. Упоминание термина «номофобия» в новостном фоне;

8. Динамика популярности темы «интернет-зависимость» в google-запросах;

9. Упоминание термина «кибербезопасность» в новостном фоне (в данном показателе отражаются несколько других: кибербуллинг, киберзапугивание, мошенничество в сети и так далее);

10. Количество детей в возрасте от 10 до 19 лет;

11. Динамика популярности темы «интернетказино» в google-запросах.

Представим выделенные факторы в виде концептуальной модели, определяющей взаимовлияние факторов (рис. 1)

Далее проведем анализ данных представленных в концептуальной модели при помощи высокоуровневого языка программирования Python, который позволяет быстро и с высокой долей объективности получить результаты по значимости влияния факторов на исследуемый признак [10, 11].

Используемые данные, в частности, упоминание какого-либо термина были получены с помощью кода в Python (рис. 2.), динамика популярности с помощью сайта Google Trends, остальные данные были взяты с сайта федеральной службы государственной статистики и с сайта единой межведомственной информационностатистической системы (ЕМИСС).

В самом начале импортируется библиотека GoogeNews, после чего большая часть кода посвящается формированию команд для выбор- 


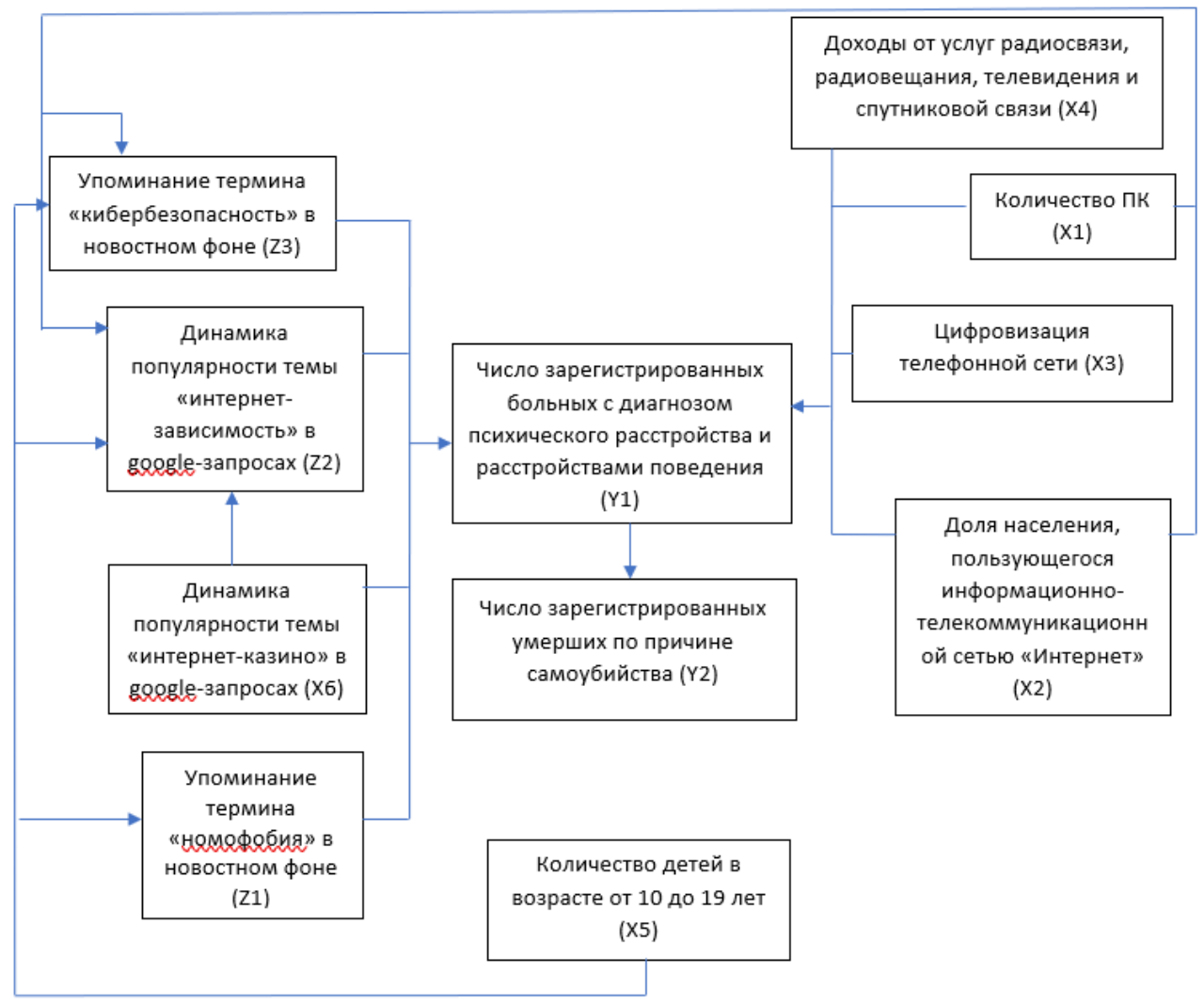

Puc. 1. Концептуальная модель влияния информационной среды на психологическое благополучие человека

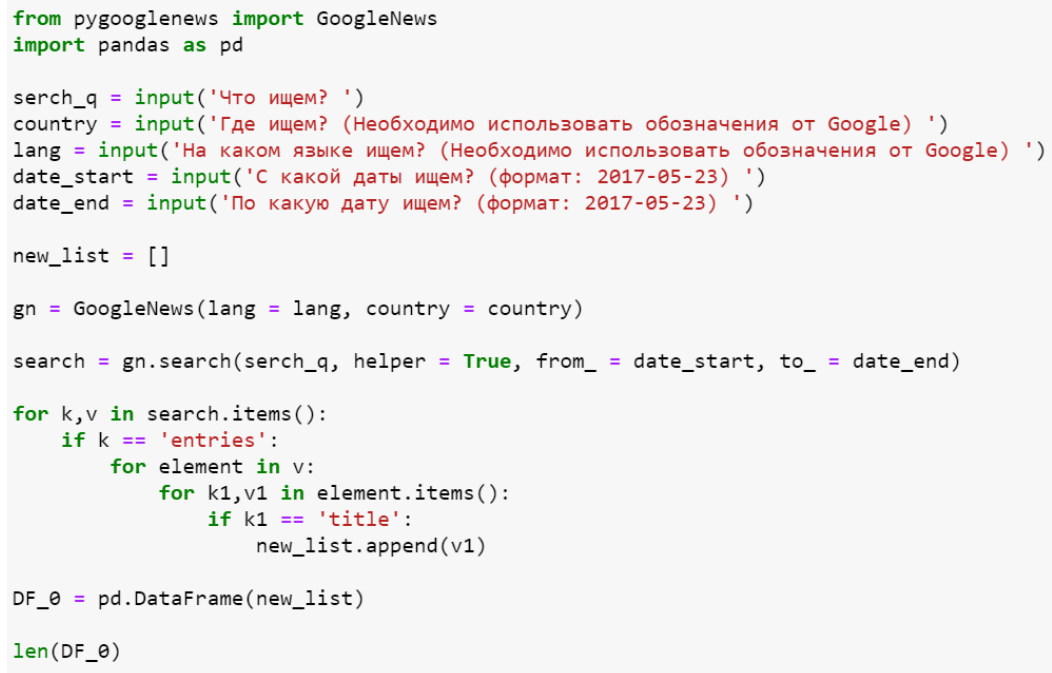

Puc. 2. Код в браузерном графическом интерфейсе Jupiter для Python

ки новостей: поиск их по ключевому слову или словам, в новостном фоне определенной страны, на конкретном языке и за определенной период времени. Самая последняя строка "len(DF_0)" предназначена просто для подсчета количества найденных и отобранных новостей.

Далее составим потенциальные уравнения регрессии:

$$
\begin{aligned}
& \mathrm{Y} 1=\mathrm{a} 1+\mathrm{b} 1 * \mathrm{X} 1+\mathrm{b} 2 * \mathrm{X} 2+\mathrm{b} 2 * \mathrm{X} 3+\mathrm{b} 3 * \mathrm{X} 4+ \\
& \mathrm{b} 4 * \mathrm{Z} 1+\mathrm{b} 5 * \mathrm{Z} 2+\mathrm{b} 6 * \mathrm{Z} 3+\mathrm{b} 7 * \mathrm{X} 6 ; \\
& \mathrm{Y} 2=\mathrm{a} 2+\mathrm{b} 8 * \mathrm{Y} 1 ; \\
& \mathrm{Z} 1=\mathrm{a} 3+\mathrm{b} 9 * \mathrm{X} 5 \\
& \mathrm{Z} 2=\mathrm{a} 3+\mathrm{b} 10 * \mathrm{X} 1+\mathrm{b} 11^{*} \mathrm{X} 2+\mathrm{b} 12 * \mathrm{X} 5+\mathrm{b} 13 * \mathrm{X} 6 ; \\
& \mathrm{Z} 3=\mathrm{a} 4+\mathrm{b} 14 * \mathrm{X} 1+\mathrm{b} 15 * \mathrm{X} 2+\mathrm{b} 16 * \mathrm{X} 5 .
\end{aligned}
$$


Выделим аналитические критерии и ограничения исследования:

1. F-критерий должен быть выше табличного;

2. Р-уровень каждого параметра в уравнении не должен превышать 10\%, если р-уровень параметра выше 0,1, то необходимо удалить этот параметр для оптимизации модели;

3. В остатках должна отсутствовать автокорреляция, иначе в остатках останется часть важной информации, которая будет утрачена.

В результате проведенного исследования были выявлены финальные оптимизированные уравнения регрессии, которые имеют следующий вид:

$$
\begin{gathered}
\mathrm{Yt}=\mathrm{Yt}-1-146011,99+110892,29 *(\mathrm{X} 3 \mathrm{t}-\mathrm{X} 3 \mathrm{t}-1) \\
\mathrm{Y} 2=\mathrm{Y} 2+231362,66-0,023 * \mathrm{Y} 1-0,0282 * \mathrm{Y} 1(\mathrm{t}-3) \\
\mathrm{Z} 2=\mathrm{Z} 2 \mathrm{t}-1+2,678+0,0033^{*}(\mathrm{X} 5 \mathrm{t}-\mathrm{X} 5 \mathrm{t}-1)- \\
0,164 *(\mathrm{X} 6 \mathrm{t}-\mathrm{X} 6 \mathrm{t}-1)-0,486 *(\mathrm{X} 2 \mathrm{t}-2-\mathrm{X} 2 \mathrm{t}-3)
\end{gathered}
$$

Фактически результатом оптимизации и анализа можно считать:

Для первого уравнения - опровержение влияния большинства независимых переменных на Y1, подтвердилась лишь одна связь: влияние доли цифровизации телефонной сети. С ее увеличением увеличивается и число зарегистрированных больных с диагнозом психического расстройства и расстройствами поведения.

Для второго уравнения - подтверждение влияния переменной Ү1 на Ү2, однако с временным лагом равным трем годам. С увеличением числа зарегистрированных больных с диагнозом психического расстройства и расстройствами поведения число зарегистрированных умерших по причине самоубийства уменьшается. При увеличении числа зарегистрированных больных с диагнозом психического расстройства и расстройствами поведения на $1 \%$ количество самоубийств уменьшится от 1\% до 7,5\%.

Для третьего - влияние изменения количества детей в возрасте от 10 до 19 лет на упоминание номофобии в новостях не подтвердилось.
Для четвертого - опровержение влияния большинства независимых переменных на Y1, подтвердились лишь две связи: влияние количества детей и доли населения, пользующегося информационно-телекоммуникационной сетью «Интернет», и то, последний показатель оказывает очень незначительное влияние. С увеличением первого увеличивается и динамика популярности темы «интернет-зависимость» в google-запросах. При увеличении количества детей в возрасте от 10 до 19 лет на 1\% динамика популярности темы «интернет-зависимость» в google-запросах увеличилась с 1,6\% до 10,4\%.

Для пятого - влияние изменения количества персональных компьютеров, доли населения, пользующегося информационнотелекоммуникационной сетью «Интернет» и количества детей в возрасте от 10 до 19 лет на упоминание кибербезопасности в новостях не подтвердилось.

Таким образом, для изменения исследуемого показателя - числа зарегистрированных больных с диагнозом психического расстройства и расстройствами поведения, необходимо оказывать влияние на уровень цифровизации телефонной сети.

Подтвердившиеся связи остальных показателей друг с другом, несомненно, важны, однако по результатам моего исследования не оказывают влияния на ключевой фактор, а, следовательно, управлять не имеет смысла.

Исходя из полученных результатов стоит обратить внимание на процесс взаимодействия молодых людей с ИКТ и проводить работу как с пользователями сети, так и с ресурсами, из которых они получают информацию. Возможно стоит разработать надстройки, позволяющие отсекать негативный и агрессивный фон от молодых людей. При этом, необходимо проводить дальнейшие более глубокие исследования в области влияния информационной среды на психологическое здоровье человека, так как процесс цифровой трансформации будет поднимать данную проблему все острее.

\section{Библиографический список}

1. Catonе G. [идр.].The drawbacks of Information and Communication Technologies:Interplay and psychopathological risk of nomophobia and cyber-bullying, results from the bullying and youth mental health Naples study (BYMHNS) // Computers in human behavior. 2020. (113). C. 106496.

2. Cénat J.M. Globalization, internet and psychiatric disorders: Call for research and action in global mental health // Neurology, Psychiatry and Brain Research. 2020. (36). C. 27-29. 
3. Gио $W$. [и др.]. Internet addiction severity and risk for psychopathology, serious mental illness, and suicidalities: a cross-sectional study // The Lancet. 2019. (394). C. S88.

4. McCrory A., Best P., Maddock A. The relationship between highly visual social media and young people's mental health: A scoping review // Children and Youth Services Review. 2020. (115). C. 105053.

5. Miranda D.M.de [и др.]. How is COVID-19 pandemic impacting mental health of children and adolescents? // International Journal of Disaster Risk Reduction. 2020. C. 101845.

6. Panova T., Lleras A. Avoidance or boredom: Negative mental health outcomes associated with use of Information and Communication Technologies depend on users' motivations // Computers in Human Behavior. 2016. (58). C. 249-258.

7. Лямин Б. М. Теоретические аспекты инновационно-инвестиционной деятельности предприятий торговой отрасли [Текст] // Интеллект. Инновации. Инвестиции. 2018. (5). С. С. 20-25.

8. Ежевская Т.И. Психологическое воздействие информационной среды на современного человека // Психопедагогика в правоохранительных органах. 2009. № 2.

9. Задохина Н. В., Попов Г.Г. Психологическое воздействие информационной среды на современного человека // Вестник Московского университета МВД России. 2016. № 7.

10. Конникова О. А., Конников Е.А. Синтаксический анализ поведения потребителей в цифровой среде 2020.С. $132-145$

11. Родионов Д. Г., Ялымов С. В., Конников Е. А. Влияние информационной среды на субъекты малого и среднего предпринимательства // Экономические науки. 2020. № 189. С. 86-91.

12. Шевченко Н. Н., Лямин Б. М. Особенности стратегического управления инновационными проектами в современных условиях // Научное обозрение: теория и практика. 2018. № 12. С. 36-43. 